\title{
The comparative value of amantadine and levodopa
}

\author{
Vera Dallos \\ B.Sc., M.R.C.P. \\ Patricia Stone \\ B.Pharm., M.P.S.
}
KENNETH HeATHFIELD
M.D., F.R.C.P.

Frank Allen

F.P.S., D.B.A.

\author{
Whipps Cross Hospital, London, E.11
}

\begin{abstract}
Summary
Sixty-nine patients with Parkinson's disease were randomly allocated in a trial to compare the therapeutic effects of levodopa and amantadine. The patients were assessed clinically and scored by occupational therapy tasks and degrees of disability. Both drugs were used for 2 months; in the first 4 weeks the doses were gradually increased to $\mathbf{4 0 0} \mathbf{~ m g}$ of amantadine or $4 \mathrm{~g}$ of levodopa respectively, and in the second 4 weeks' period the maximum tolerated dose was maintained throughout. Fourteen patients withdrew and these were excluded from the series. Of the fifty-five patients who completed the trial, thirty-four were taking levodopa and twenty-one amantadine.

The results showed an average $33 \%$ improvement on levodopa and $23 \%$ on amantadine as regards tremor, rigidity and akinesia and their total scores improved $26 \%$ and $18 \%$ respectively. More cases showed substantial improvement on levodopa.

There was little difference in response between 200 and $400 \mathrm{mg}$ amantadine daily, but side-effects with $400 \mathrm{mg}$ amantadine daily were more frequent and severe. Side-effects with levodopa were similar to those reported in previous trials but we also noted brown body fluids in three patients. The average effective dose of levodopa was lower than in previous reports, and the largest number of patients received benefit from $1.5 \mathrm{~g}$ daily. The superior effect of levodopa was shown.
\end{abstract}

\section{Introduction}

Previous authors have attempted to compare the relative value of amantadine and levodopa in the treatment of Parkinson's disease (Fieschi et al., 1970). Both of these drugs have been proven to be of use but Hunter et al. (1970) considered that amantadine is less effective than levodopa. Other workers (Rao \& Pearce, 1971) have found the value of amantadine to be comparable with that of levodopa. In 1970 we reported (Dallos et al.) the results of a double blind trial of amantadine $200 \mathrm{mg}$ daily used with a placebo and found it to be of moderate but definite value. We therefore decided to use the patients from this trial to compare the effects of amantadine in a larger dose of $400 \mathrm{mg}$ daily against levodopa $4 \mathrm{~g}$ daily.

\section{Method}

Sixty-nine patients were treated with amantadine or levodopa; forty-two were given levodopa ,twentyseven amantadine. Forty-two of the patients had taken part in the previous trial and there were twenty-seven new patients. Eighteen of the 'old' patients had been taking amantadine and twentyfour had been on the placebo, and half of each of these were randomly allocated either to the increasede dose of amantadine or levodopa. New patients were similarly divided but there was some bias in favour of levodopa. The following dosage scheme was planned: the patients on amantadine were started on $100 \mathrm{mg}$ daily for the first week and the dose was increased by $100 \mathrm{mg}$ daily each successive week till they were taking $\mathbf{4 0 0} \mathrm{mg}$ daily. During the second month this dose was maintained. Similarly, the patients on levodopa were given $1 \mathrm{~g}$ in the first week and 2, 3 and $4 \mathrm{~g}$ daily in the successive weeks and during the second month of the trial it was planned to give $4 \mathrm{~g}$ daily throughout.

Although we had planned to compare the effects of levodopa $4 \mathrm{~g}$ daily with amantadine $400 \mathrm{mg}$ daily, the majority of patients were not able to tolerate these doses and eventually the results compared patients on the maximum tolerated dose of each drug. On amantadine these were $200 \mathrm{mg}$ daily in three patients, $300 \mathrm{mg}$ daily in two patients, and $400 \mathrm{mg}$ daily in sixteen patients. The maximum tolerated dose of levodopa was $0 \cdot 25-1 \mathrm{~g}$ daily in five patients, $1.5-2.0 \mathrm{~g}$ in fifteen patients and $2-4 \mathrm{~g}$ in fourteen patients.

Fifty percent of the levodopa group but only $30 \%$ of the amantadine group were men. There was no marked difference in the ages of the two groups; the average age of the levodopa group was $62 \cdot 4$ years and the amantadine group 63.5 years.

Patients were scored by the same method that was 
used in the previous trial (Dallos et al., 1970) and by the same workers. The patients were scored weekly for rigidity, tremor and akinesia and monthly for disability and occupational therapy tasks. As in the previous trial the results were expressed as percentages of the initial score. We scored rigidity, tremor and akinesia separately and then these were combined. Similarly, disability and occupational therapy (OT) tasks were scored separately and then combined; finally the total scores incorporating all five categories were compared.

\section{Results}

Fifty-five patients completed the trial; thirty-four of them were on levodopa and twenty-one on amantadine. Of the fourteen failures, eight were on levodopa and six were on amantadine. Their scores were not included in the results but reasons for failures are given in Table 1.

TABLE 1. Failures of treatment

\begin{tabular}{ll}
\hline Levodopa & \\
Side-effects & 3 \\
Died (aspiration pneumonia) & 1 \\
Withdrew dissatisfied & 2 \\
Unable to co-operate & 2 \\
$\quad$ Total & 8 \\
Amantadine & \\
Severe mental disturbance & 4 \\
Withdrew dissatisfied & 2 \\
$\quad$ Total & 6 \\
\hline
\end{tabular}

The effects of the drugs on the scores for rigidity, tremor and akinesia both separately and combined at weekly intervals, are shown in Table $2(a-d)$. Rigidity showed continuous steady improvement with levodopa throughout the 8 weeks, whereas in patients taking amantadine, rigidity improved till 6 weeks after which a mild deterioration occurred. At the end of 8 weeks, the levodopa group had improved $41 \%$ and the amantadine group $32 \%$. Similar results were found in the assessments of tremor and akinesia in both of which the effects of the drugs were parallel up to 5 weeks after which slight deterioration occurred in those on amantadine. After 8 weeks' treatment, tremor had improved $36 \%$ in levodopa cases and $19 \%$ in amantadine patients. Akinesia improved $27 \%$ on levodopa and $20 \%$ on amantadine. The combined scores showed the same general trend, the percentage improvements being 33 and 23 respectively.

The results for disability and occupational therapy tasks which were assessed at monthly intervals are shown in Table 3. These show the difference in the efficacy of the two drugs. This difference is statistically significant in the disability scores but only of borderline significance in the OT tests. The combined scores show differences of intermediate value.

The total scores are shown in Table 4. It will be seen that the levodopa cases improved by $26 \%$ as against $15 \%$ for amantadine. This difference is significant at $P<0.02$ level.

As regards the degree of improvement we found that three patients on levodopa but none on amantadine made a $50 \%$ improvement in the total score (see Table 5). Twelve on levodopa and one on amantadine showed improvement between $30 \%$ and $49 \%$ and eleven on levodopa and fifteen on amantadine improved between $10 \%$ and $29 \%$. Eight patients on levodopa and five on amantadine were unchanged.

\section{Side-effects \\ Amantadine}

Nineteen of the twenty-one patients taking amantadine $\mathbf{4 0 0} \mathrm{mg}$ daily had side-effects and four had to discontinue treatment. The others responded to reduction of the dose. All side-effects occurred in doses exceeding $200 \mathrm{mg} /$ day and most of them on $400 \mathrm{mg} /$ day. Four patients, all of whom had been previously treated by psychiatrists, developed severe mental symptoms and treatment had to be dis-

TABLE 2. Rigidity, tremor, akinesia. Mean scores at each assessment as percentage of initial score

\begin{tabular}{|c|c|c|c|c|c|c|c|c|c|}
\hline & \multicolumn{9}{|c|}{ Week } \\
\hline & 0 & 1 & 2 & 3 & 4 & 5 & 6 & 7 & 8 \\
\hline $\begin{array}{l}\text { (a) Rigidity } \\
\text { Levodopa (34) } \\
\text { Amantadine (21) }\end{array}$ & $\begin{array}{l}100(=7 \cdot 24) \\
100(=5 \cdot 10)\end{array}$ & $\begin{array}{l}93 \\
87\end{array}$ & $\begin{array}{l}89 \\
85\end{array}$ & $\begin{array}{l}81 \\
84\end{array}$ & $\begin{array}{l}67 \\
73\end{array}$ & $\begin{array}{l}63 \\
69\end{array}$ & $\begin{array}{l}61 \\
63\end{array}$ & $\begin{array}{l}61 \\
69\end{array}$ & $\begin{array}{l}59 \\
68\end{array}$ \\
\hline $\begin{array}{l}\text { (b) Tremor } \\
\text { Levodopa (34) } \\
\text { Amantadine (21) }\end{array}$ & $\begin{array}{l}100(=4 \cdot 15) \\
100(=3 \cdot 81)\end{array}$ & $\begin{array}{l}100 \\
105\end{array}$ & $\begin{array}{l}89 \\
99\end{array}$ & $\begin{array}{l}79 \\
82\end{array}$ & $\begin{array}{l}66 \\
71\end{array}$ & $\begin{array}{l}77 \\
67\end{array}$ & $\begin{array}{l}71 \\
70\end{array}$ & $\begin{array}{l}68 \\
76\end{array}$ & $\begin{array}{l}64 \\
81\end{array}$ \\
\hline $\begin{array}{l}\text { (c) Akinesia } \\
\text { Levodopa (34) } \\
\text { Amantadine (21) }\end{array}$ & $\begin{array}{l}100(=12 \cdot 59) \\
100(=10 \cdot 43)\end{array}$ & $\begin{array}{l}90 \\
94\end{array}$ & $\begin{array}{l}86 \\
82\end{array}$ & $\begin{array}{l}78 \\
79\end{array}$ & $\begin{array}{l}76 \\
83\end{array}$ & $\begin{array}{l}74 \\
78\end{array}$ & $\begin{array}{l}73 \\
83\end{array}$ & $\begin{array}{l}76 \\
78\end{array}$ & $\begin{array}{l}73 \\
80\end{array}$ \\
\hline $\begin{array}{l}\text { (d) Combined } \\
\text { Levodopa (34) } \\
\text { Amantadine (21) }\end{array}$ & $\begin{array}{l}100(=23.97) \\
100(=19 \cdot 33)\end{array}$ & $\begin{array}{l}98 \\
94\end{array}$ & $\begin{array}{l}88 \\
86\end{array}$ & $\begin{array}{l}79 \\
81\end{array}$ & $\begin{array}{l}72 \\
78\end{array}$ & $\begin{array}{l}72 \\
73\end{array}$ & $\begin{array}{l}69 \\
75\end{array}$ & $\begin{array}{l}70 \\
75\end{array}$ & $\begin{array}{l}67 \\
77\end{array}$ \\
\hline
\end{tabular}


TABLe 3. Disability and OT tests. Mean scores at weeks 4 and 8 as percentage of initial score

\begin{tabular}{lccc}
\hline & \multicolumn{3}{c}{ Week } \\
\cline { 2 - 4 } & 0 & 4 & 8 \\
\hline $\begin{array}{l}\text { Disability } \\
\text { Levodopa } \\
\text { Amantadine }\end{array}$ & $100(=7 \cdot 79)$ & 76 & 70 \\
OT tests & $100(=6 \cdot 19)$ & 84 & 82 \\
$\quad$ Levodopa & $100(=17 \cdot 00)$ & 91 & 87 \\
$\quad$ Amantadine & $100(=14 \cdot 86)$ & 95 & 95 \\
$\begin{array}{l}\text { Disability and OT } \\
\text { tests combined } \\
\quad \text { Levodopa } \\
\text { Amantadine }\end{array}$ & $100(=24 \cdot 79)$ & 86 & 82 \\
& $100(=21 \cdot 05)$ & 92 & 91 \\
\hline
\end{tabular}

TABle 4. Total scores. Mean scores at weeks 4 and 8 as percentage of initial score

\begin{tabular}{lccc}
\hline & \multicolumn{3}{c}{ Week } \\
\cline { 2 - 4 } & 0 & 4 & 8 \\
\hline Levodopa & $100(48 \cdot 77)$ & 79 & 74 \\
Amantadine & $100(40 \cdot 38)$ & 85 & 85 \\
\hline
\end{tabular}

TABLE 5. Categories of improvement

\begin{tabular}{|c|c|c|c|c|c|}
\hline & \multirow{3}{*}{$\begin{array}{l}\% \text { reduction } \\
\text { of total score }\end{array}$} & \multicolumn{4}{|c|}{$\begin{array}{c}\text { Number and } \% \text { of } \\
\text { patients in each group } \\
\text { at week } 8\end{array}$} \\
\hline & & \multicolumn{2}{|c|}{$\begin{array}{l}\text { Levo- } \\
\text { dopa }\end{array}$} & \multicolumn{2}{|c|}{$\begin{array}{c}\text { Amant- } \\
\text { adine }\end{array}$} \\
\hline & & No. & $\%$ & No. & $\%$ \\
\hline $\begin{array}{l}\text { Much improved } \\
\text { Moderately } \\
\text { improved } \\
\text { Slightly } \\
\text { improved } \\
\text { No change } \\
\text { Worse }\end{array}$ & $\begin{array}{l}50 \% \text { or more } \\
\text { reduction } \\
30 \text { to } 49 \% \\
\text { reduction } \\
10 \text { to } 29 \% \\
\text { reduction } \\
9 \text { to }-9 \% \\
\text { reduction } \\
-9 \text { to }-43 \% \\
\text { reduction }\end{array}$ & $\begin{array}{r}3 \\
12 \\
11 \\
7 \\
1 \\
34\end{array}$ & $\begin{array}{l}35 \\
32 \\
21\end{array}$ & $\begin{array}{r}15 \\
4\end{array}$ & $\begin{array}{r}5 \\
71 \\
19 \\
5 \\
100\end{array}$ \\
\hline
\end{tabular}

continued. The four patients developing visual hallucinations were on amantadine alone as were the two who became mentally confused. Nine patients developed oedema of the ankles; in two this was due to hypertensive cardiac failure and in these the oedema responded to oral diuretics and reduction of the dose of amantadine. In the other seven patients the oedema was unexplained. No biochemical or clinical evidence of cardiac, renal or liver disease was found. Two cases developed paroxysmal supraventricular tachycardia, again responding to reduction of the dose.

\section{Levodopa}

Three of the thirty-four patients on levodopa were taken out of the trial because of side-effects. Gastrointestinal symptoms were the commonest; nausea and vomiting usually occurred within the first 4 weeks of treatment when the dose was being increased and usually responded to reduction of dose and the addition of anti-emetics - we used cyclizine $25-50 \mathrm{mg}$ three times a day. No tolerance developed to these symptoms and anti-emetics were required throughout treatment but improvement was obtained by taking the levodopa $\frac{1}{2} \mathrm{hr}$ after meals and giving small doses frequently. A patient with postencephalitic parkinsonism who vomited on a dose of $500 \mathrm{mg}$ daily was the only one who left the trial because of this symptom. Nine patients complained of anorexia throughout the trial but weight loss occurred only in two.

Involuntary movements were a late effect related both to the dose and duration of the treatment. They required reduction of dose but in two patients treatment had to be discontinued. In one patient levodopa was restarted after 8 weeks, but involuntary movements of the head returned after taking $500 \mathrm{mg}$ daily for only two days. The full range of involuntary movements previously recorded was found. Two patients developed laryngeal stridor which subsidedô on discontinuing the treatment but recurred on re starting it. Transient dizziness, especially $\frac{1}{2}-1 \mathrm{hr}$ after the morning dose, was noted in eleven patients but? ceased spontaneously.

Depression, nightmares and visual hallucinations occurred in patients who had had these symptoms previously from anticholinergic drugs. In two cases visual hallucinations occurred when levodopa was added to benzhexol and the symptoms subsided when the dose of benzhexol was reduced.

Postural hypotension with falls of more than $20 \mathrm{mmHg}$ systolic and diastolic blood pressure occurred in seventeen cases. In eleven patients the hypotension was asymptomatic but in six cases symptoms occurred. The fall of systolic blood pressure varied from 20 to $70 \mathrm{mmHg}$ (the commonest being $30 \mathrm{mmHg}$ ) and the fall of diastolic blood pressure from 20 to $30 \mathrm{mmHg}$ (the commonest being $20 \mathrm{mmHg}$ ). The variation of blood pressures were the same whether or not symptoms occurred. The dose of levodopa was reduced in five patients with symptoms but the blood pressure of the sixth patient rose without reduction. The fall in blood pressure was not related to the initial level.

Three patients noted transient brown body fluids during the first or second week of treatment. One noted brown smoky urine, another brown vaginal discharge and a third patient brown saliva. Investigations in all three failed to reveal bleeding as the cause. 


\section{Discussion}

The therapeutic effects of amantadine and levodopa were compared at their maximum tolerated dose levels. In our previous report (Dallos et al., 1970) amantadine in a dose of $200 \mathrm{mg}$ daily was found to improve all facets of parkinsonism by $20 \%$ over 4 weeks; side effects were negligible.

In the present trial we used $400 \mathrm{mg}$ amantadine daily and found that when it was tolerated the increased therapeutic benefit compared with $200 \mathrm{mg}$ daily was insignificant. Side-effects were severe in nineteen patients and required the reduction of dose to $200 \mathrm{mg}$ daily in thirteen and discontinuation of treatment in four because of psychiatric symptoms. The latter were patients with a previous history of anxiety and depression.

The commonest side-effect was swelling of the ankles and this has been reported previously by Parkes et al. (1970). Shealy, Weeth \& Mercier (1970) reported livedo reticularis developing in patients on amantadine in association with oedema and we have also seen several instances though not in patients in this series. The concurrence of livedo and oedema supports the view that the latter may be due to damage to the capillaries.

In all the cases on amantadine optimal effect was obtained in 5 weeks and usually maintained at a slightly lower level thereafter. Drug interaction was observed between amantadine and both anticholinergic and sympathomimetic drugs, the former producing visual hallucinations and the latter retention of urine and an agitated mental state; Schwab, Poskanzer \& Young (1969) also described this interaction with anticholinergic drugs.

From our results we recommend that amantadine should not be given in doses greater than $200 \mathrm{mg}$ daily; nor should it be administered to patients with a previous history of severe anxiety or depression. It may well be the drug of choice in postencephalitic parkinsonism where tolerance to levodopa has been found to be reduced (Hunter et al., 1970). Two of our patients could not even tolerate $500 \mathrm{mg}$ of levodopa daily although they improved on amantadine.

Levodopa is the more effective drug and Fieschi et al. (1970) obtained twice the degree of improvement than with amantadine. Although our results were less favourable than theirs, it should be noted that all the levodopa-treated cases in our series were severely disabled and their disability score was higher than the scores of the patients treated with amantadine.

Side-effects with levodopa were many and required frequent re-adjustment of dose. Hughes et al. (1971) reported a similar range of side effects. Gastrointestinal, mental and circulatory symptoms occurred in the earlier stages and involuntary movements in the later stages. The latter was the commoner reason for discontinuation of levodopa.
In view of our findings of three patients with brown secretions, we consider that patients should be warned of the occurrence of these as a possible sideeffect. Sandler, Karonum \& Ruthers (1970) suggested that this might be due to breakdown products such as homogentisic acid.

Drug interaction also occurred between levodopa and anticholinergic drugs producing visual hallucinations. Levodopa acts synergistically with reserpine and methyldopa in lowering the blood pressure. This was found to be advantageous in hypertensive patients as it allowed for reduction or discontinuation of hypotensive drugs which might potentially aggravate parkinsonism by depleting dopamine stores in the basal ganglia.

After 8 weeks on levodopa the treatment was often not stabilized and neither optimal benefit nor optimal dosage were established. Levodopa is a slowacting drug that requires long-term supervision as side-effects also were often late in appearing.

This trial, a sequel to one demonstrating the early effectiveness of amantadine either alone or with standard anti-parkinsonian drugs, confirms the results of the first trial. For a true comparison of effectiveness of amantadine and levodopa the 2month period proved too short to demonstrate the final improvement on levodopa. Nevertheless the trial clearly showed the overall superiority of the latter drug.

\section{Acknowledgments}

We are grateful to Dr Michael Simister of Ward Blenkinsop Pharmaceuticals Limited and Dr Alan Galbraith of Geigy (U.K.) Limited, for supplies of levodopa and amantadine and for technical help, and to Dr Lewis Faning who analysed the statistics. We are also indebted to members of the Occupational Therapy department of Whipps Cross Hospital for their help and Sister Stafford in the Out-patient Department. Thanks are also due to Dr D. Scott of the London Hospital for his advice, to Dr P. Marshall-Jones and Dr A. J. Brafield in the Department of Pathology of Whipps Cross Hospital for their help and to Mrs G. Quant for the secretarial work.

\section{References}

Dallos, V, Heathfield, K, Stone, P. \& Allen, F.A.D. (1970) Use of amantadine in Parkinson's Disease. Results of a double blind trial. British Medical Journal, 4, 24.

Fieschi, C., Nardin, M., Casacchia, M., Tedone, M.E. \& ReITANI, M. (1970) Amantadine versus levodopa and amantadine plus levodopa. Lancet, ii, 154.

Godwin-Austen, R.B., Frears, C.C. \& BergmanN, S. (1971) Incidence of side-effects from levodopa during the introduction of treatment. British Medical Journal, 1, 267

Hughes, R.C., Polgar, J.G., Weightman, D. \& Walton, J.N. (1971) Levodopa in Parkinsonism and the influence of previous thalamotomy. British Medical Journal, 1, 7.

Hunter, K.R., Stern, G.M., LAurence, D.R. \& ARmitage, P. (1970) Amantadine in parkinsonism. Lancet, i, 1127.

PARKes, J.D., Zilkha, K.J., MARSDen, P., BAXTeR, R.C.H. \& KNILl-Jones, R. (1970) Amantadine dosage in treatment of Parkinson's disease. Lancet, i, 1130.

RaO, N.S. \& Pearce, J. (1971) Amantadine in parkinsonism. An extended prospective trial. Practitioner, p. 241. 
Sandler, M., Karoum, F. \& Ruthyen, C.R.J. (1970)

Parkinsonism with alkaptonuria: A new syndrome? Lancet, ii, 770.

Shealy, C.N., Weeth, J.B. \& Mercier, D. (1970) Livedo reticularis in patients with parkinsonism receiving amanta- dine. American Medical Association, 212, 9.

Schwab, R.S., England, A.C., Poskanzer, D.C. \& Young, R.R. (1969) Amantadine in the treatment of Parkinson's disease. Journal of the American Medical Association, 208, 1168. 